\title{
Another attempt at creating a global vaccine initiative
}

If the promises are fulfilled, last month should prove memorable for vaccine research and global immunization programs. An international alliance of philanthropic foundations, government ministers, pharmaceutical companies, United Nations agencies and the World Bank announced the formation of a new organization dedicated to immunizing third-world children with available vaccines, and stated its intention to invest in $R \& D$ for vaccines for malaria, tuberculosis and AIDS. In his State of the Union address, President Clinton proposed "a tax credit to speed the development" of vaccines for these diseases. And the National Institutes of Allergy and Infectious Diseases announced an agreement to accelerate malaria vaccine development with the Seattle-based Program for Appropriate Technology in Health (PATH).

The Global Alliance for Vaccines and Immunizations (GAVI) was formed last year (Nature Med. 5, 249; 1999), and although it is chaired by Gro Harlem Bründtland, director-general of the World Health Organization, who will be succeeded in two years by Carol Bellamy, executive director of UNICEF, it is dominated by funds from the Bill and Melinda Gates Foundation, which is rapidly becoming the most influential philanthropic health body on the public scene.

Fund-raising and galvanizing participating organizations into effective collaboration have been the bête noire of previous children's vaccine programs (Nature Med. 5, 469; 1999), and GAVI is already looking for contributions for its first initiative, "The Children's Challenge," which is described as a "global campaign to help educate and enlist the support of individuals and institutions in the effort to immunize the world's children." Fortunately, the challenge is supported by the Gates
Foundation's Global Fund for Children's Vaccines (established through PATH), which has a five-year endowment of $\$ 750$ million. Such sums of money dwarf contributions from other sources. For example, the challenge only has a promise that Vice President Al Gore will ask Congress for \$50 million support.

And unlike previous efforts whose unattained goals included the enticement of private investment in the development and distribution of vaccines for developing countries, GAVI's chances of success have been increased by co-opting the six leading vaccine manufacturing pharmaceutical companies (Aventis, Pasteur Merieux, SmithKline Beecham, American Home Products, Merck, Chiron Vaccines, BERNA Swiss Serum and the Vaccine Institute Berne) as full partners.

Karen Birmingham, London

\section{Spanish oncologists square-up}

Only eight months after the foundation stone was laid for a new cancer research center near Madrid (Nature Med. 5, 722; 1999), Spain is celebrating the opening of a second such research facility.

The new center, the Salamanca Cancer Research Center at the University of Salamanca, boasts US\$9.1 million funding, 20 laboratories and 200 scientists. Its establishment also pits two of the country's most experienced cancer researchers head-to-head.

Eugenio Santos, who returned to Spain last year after 17 years at the US National Institutes of Health (NIH), will direct the Salamanca center. Oncologist Mariano Barbacid, who worked in the US at the NIH and pharmaceutical company Bristol-Myers Squibb for a total of 25 years, directs the larger Madrid facility (the National Center of Cancer Research (CNIO)) due to become fully operational in January 2001.

Santos aims to collaborate with pharmaceutical companies to increase the center's budget, and to establish links with Spain's other cancer research institutes, especially Barbacid's CNIO and the Department of Oncology Immunology (DOI), to create a coordinated cancer research network.

Barbacid says he will be "delighted" to cooperate with Santos and does not foresee a duplication of efforts, but adds that he sees the Salamanca center's separation into 20 groups as a handicap because it may create intellec-

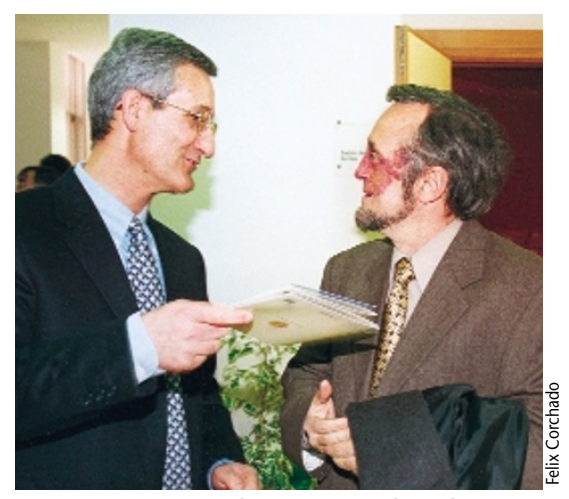

Eugenio Santos and Mariano Barbacid reply, Santos voiced his opinion on Barbacid's center, saying that it must be careful not to focus too heavily on basic research at the expense of clinical studies, for example by "stagnating on knockout mice models." He says his own group "already has several clinical patents covering molecular diagnosis of leukemia." DOI head Carlos Martínez-A does not consider that the co-existence of both centers disadvantageous, tual and practical divisions in research activity. Furthermore, he is skeptical as to how effectively the center can raise private funds because of its part-state ownership under the Higher Council of Scientific Research (CSIC). By way of and insists it means "more jobs in biomedical research" and "a means of ensuring Spain's competition in cancer research."

Xavier Bosch, Barcelona 